\title{
Connectors and coordinators in natural resource governance: insights from Swiss water supply
}

\author{
Mario Angst $^{1,2}$, Alexander Widmer $^{1}$, Manuel Fischer ${ }^{1,2}$ and Karin Ingold $^{1,2,3}$
}

\begin{abstract}
Fragmentation across scales in natural resource governance can impede coordinated action and decrease innovation capacity. Bridging actors who connect others within governance networks helps to overcome this challenge. We analyze two bridging positions for actors in governance networks. First, periphery connectors integrate otherwise unconnected actors and provide access to new knowledge. Second, central coordinators efficiently connect actors at the center of the network and thus facilitate coordinated action. We propose a way to identify periphery connectors and central coordinators within governance networks and formulate expectations about types of actors that are likely to occupy these positions. An analysis of three actor networks in the water supply sector in Switzerland suggests that periphery coordinator positions are more likely to be occupied by organizations at higher jurisdictional levels. Central coordinator positions are more likely to be occupied by governmental actors as compared to nongovernmental actors. Thus, in addressing challenges of fragmentation, higher level governmental actors continue to play an important role, even when they delegate responsibilities to lower level and private actors.
\end{abstract}

Key Words: bridging; fragmentation; governance; governance networks; natural resource governance; social network analysis; Switzerland; water supply

\section{INTRODUCTION}

Coordination in natural resource governance is a difficult task because of the involvement of many governmental and nongovernmental actors operating at different levels of spatial and jurisdictional scales (Cash et al. 2006, Ostrom 2009, PahlWostl 2009). Changes in institutions and policy designs that emphasize self-organization of actors in governance networks are one way to address the challenge of coordination (Folke et al. 2005). Collaboration between individual actors in governance networks can thus mediate the challenges of fragmented natural resource governance (Bodin and Crona 2009).

Actors within such governance networks, intentionally or inadvertently, take up different positions, which potentially contribute to coordination. For example, McAllister et al. (2014) examine how organizations influence climate change adaptation planning in Australia by playing a select set of roles within governance networks. One type of role includes organizations that interact with many other different types of organizations and are thus important for disseminating knowledge throughout a fragmented governance landscape. The study of Ernstson et al. (2008) demonstrates that a lack of organizations that integrate peripheral groups with valuable ecological knowledge into the management of urban green areas could have constrained more collaborative management. In a similar vein, Vignola et al. (2013) identify so-called bridging organizations, which transmit information across scales and policy areas, as key actors in a study of watershed management in Costa Rica.

This analysis focuses on actors who occupy bridging positions in natural resource governance networks in further detail. In general, actors in bridging positions connect other actors who would not be connected otherwise (Granovetter 1973). We focus on two types of bridging that each address an essential governance challenge resulting from fragmentation. First, bridging ties can connect peripheral actors to the network. This integrates a more heterogeneous set of actors into the network, which provides access to new knowledge to the rest of the network (Carlsson and Sandström 2008). Second, bridging ties can efficiently connect actors who need to coordinate their actions across levels of scales (Ernstson et al. 2008, Rathwell and Peterson 2012). Based on these two types of bridging ties, we analyze two actor positions in governance networks: periphery connectors and central coordinators. We then ask which actors are likely to occupy these positions.

Answers to our research question contribute to the literature in three ways. First, on a theoretical level, we develop a precise understanding of periphery connectors and central coordinators as two important bridging roles. The theoretical value of this distinction extends to the existing literature in policy studies and natural resource governance, where concepts of bridging roles are ubiquitous (Ernstson et al. 2008, Bodin and Crona 2009, Christopoulos and Ingold 2015). Our study answers the demand for a more profound analysis of individual actors occupying critical positions in natural resource governance (Bodin and Crona 2009). Second, on the methodological level, we propose a straightforward operationalization of both role concepts. Especially, we identify periphery connectors by adapting a bridging measure developed in the social network analysis literature (Valente and Fujimoto 2010). Third, on the empirical level, we provide insights into governance settings with a very high potential for fragmentation. An empirical analysis of three regions in Switzerland with different socioeconomic contexts allows us to identify the actors that are most likely to occupy periphery connector and central coordinator positions in these settings.

${ }^{1}$ Eawag: Swiss Federal Institute of Aquatic Science and Technology, ${ }^{2}$ Institute of Political Science, University of Bern, ${ }^{3}$ Oeschger Centre for Climate Change Research, University of Bern 


\section{THE ROLE OF ACTORS IN OVERCOMING FRAGMENTATION IN NATURAL RESOURCE GOVERNANCE NETWORKS}

\section{Fragmentation in natural resource governance}

Following Jasny and Lubell (2015), we define fragmentation as a setting where actors have overlapping responsibilities for issues that span across multiple levels of a relevant scale of governance, or work independently on interconnected issues. Fragmentation impedes effective governance (Carlsson and Sandström 2008, Ekstrom and Young 2009, Bodin et al. 2014) especially because of competing responsibilities between different actors (Jasny and Lubell 2015). Such competing responsibilities are a "fertile ground" for collective action dilemmas (Berardo 2014:238). By contrast, reducing fragmentation by integrating new and nonpublic actors in the governance system has the potential to include new views, information, and perspectives (Prell et al. 2009) and enhance creativity and innovation (Betsill and Bulkeley 2004).

Institutional adjustments have been suggested to reduce fragmentation. For example, the concept of institutional fit (Folke et al. 2007) suggests to better match ecological system structure with formal and informal rules (Ekstrom and Young 2009). Although adjusting institutions is thus a way to address issues of fragmentation, individual actors can also contribute to overcoming fragmentation in a governance network without institutional change.

\section{Overcoming fragmentation through bridging}

Among actors who can contribute to the reduction of fragmentation, actors in bridging positions play an important role. The literature on social networks in natural resource governance has highlighted different forms of bridging (see Fernandez and Gould 1994, McAllister et al. 2015), such as crossscale brokerage (Ernstson et al. 2010, Rathwell and Peterson 2012), within- and across-type bridging (McAllister et al. 2015), or brokering across venues or issues (Lubell 2013, Fischer et al. 2017). Although these analyses have addressed specific sources or problems of fragmentation (levels, actor types, and issues), we provide a more general division of bridging activity in regard to two main problems of fragmentation. These problems are the loss of access to new knowledge and inefficient coordination and we suggest distinguishing two essential bridging positions that can help to overcome them: periphery connectors and central coordinators.

Periphery connectors integrate otherwise unconnected actors to the core of the network. Many studies observe a core-periphery setting in governance situations, where a well-connected group of core actors can be distinguished from a loosely connected periphery (e.g., Ernstson et al. 2008, Luthe et al. 2012, Hirschi et al. 2013, Angst and Hirschi 2016). Periphery connectors maintain contact to the margins of the network and support access to and integration of new knowledge. Peripheral actors are often sources of information heterogeneity in a network because they are likely to be less prone to groupthink, sticky information (Burt et al. 2013) and homophilous processes (where actors who interact often become more similar over time) acting among strongly connected actors. Furthermore, heterogeneity has also been associated with effectiveness and adaptability in natural resource governance networks (Carlsson and Sandström 2008).
Central coordinators play a different bridging role than periphery connectors. They do not reach out to the periphery, but rather can facilitate coordinated action because of their central position. The defining characteristic of central coordinators is that they connect a great number of other actors - who might be connected to each other but over longer paths - in a very efficient way. This means that they provide the shortest network paths between many other actors, making them logical choices if one actor wants to reach other actors. Central coordinators are thus key actors if it is necessary to coordinate action and disseminate information. We focus on bridging centrality in this study, but there are various other ways actors can be central in a network. Bodin and Crona (2009) highlight several examples of how central actors can contribute to governance outcomes through information distribution and leadership that go beyond our specific focus on overcoming fragmentation. Figure 1 illustrates periphery idealtypical periphery connector (A) and central coordinator (B) positions.

Fig. 1. Illustrations of network positions of periphery connector (A) and central coordinator (B) positions.

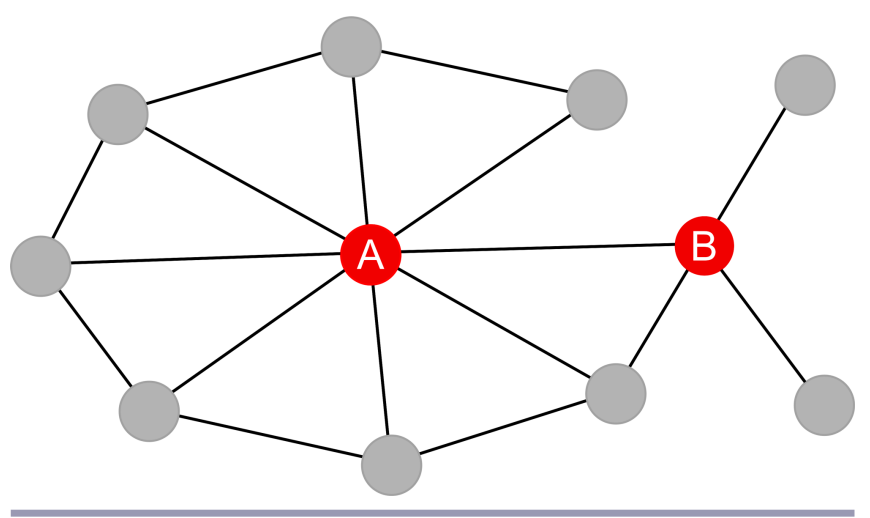

Hypotheses about distribution of positions

Some types of actors have been shown to be more likely to occupy specific positions in natural resource governance networks. For instance, Kininmonth et al. (2015) conclude that large municipalities are crucial to enhance the compatibility between the governance network structure and ecological interdependencies in wetland management. Fliervoet et al. (2016) show how nongovernmental actors depend on the resources and connections of governmental actors in new governance approaches to natural resource management. Exploring the role of local actors in regional land use planning, Ingold (2014) concludes that mainly intermediate-level actors, in contrast to local or national actors, connect different parts in multilevel networks. By contrast, Angst and Hirschi (2016) show that higher level actors such as the national administration provide stable and lasting connections and thus play a crucial role in network development over time.

Hypothesis 1: Periphery connector positions are more likely to be occupied by actors at a higher jurisdictional level than by lower level actors

Actor attributes are thus likely to influence which actors take up periphery connector and central coordinator positions. There is a line of argument within the environmental governance literature 
that stresses that directly affected, local level stakeholders are best suited to resolve resource degradation problems and thus need to be included in the decision-making process (Ostrom 2000). The involvement of actors on higher levels in a polycentric arrangement has, however, also been shown to positively affect governance outcomes, provided that these actors do interact sufficiently (Newig and Fritsch 2009). The concept of periphery connectors relates to this discussion, as it highlights a mechanism through which higher level actors can influence the effectiveness of governance in terms of ensuring sufficient interaction. Periphery connectors represent a network position that is important for assuring integration of diverse knowledge but is not necessarily (but can be) involved in the direct management of a resource. We posit that higher level actors, who are less affected by the mostly local or regional environmental problems and the related solutions, are more likely to be such periphery connectors. These actors tend to be involved in many different governance processes, compared to local level stakeholders focused on local problems. This involvement allows them to gain experiences, to transfer knowledge from one setting to another, and to access a wider network of different actors.

Hypothesis 2: Central coordinator positions are more likely to be occupied by governmental actors than by nongovernmental actors Whereas forms of self-regulation with only little direct involvement of public authorities and governmental actors became prominent steering arrangements in environmental governance (Ostrom 2009), public actors still play an important role. Effective (environmental) governance often results from actors' interaction "in the shadow of hierarchy" (Bolleyer and Börzel 2010:182). Even in settings where they surrender formal power, governmental actors can exert substantial influence by putting themselves into coordinating positions (Fliervoet et al. 2016, Fischer and Schläpfer 2017). This enables them to pursue their interests without having to rely on strategies of top-down enforcement. A similar argument is made by the literature on network management and meta-governance of networks, referring to the capacity of governmental actors to steer networks by facilitating interaction processes, mediating conflicts, and reallocating resources (Klijn and Koppenjan 2000). Besides, government and its administration are also more likely to have the necessary resources to occupy central coordinator positions, as compared to other actors. They often employ a larger, specialized workforce than other actors but most importantly, governmental actors in most cases still maintain the formal responsibility to initiate and structure policy processes. Consequently, they are often the preferential targets for collaboration for other actors (Leifeld and Schneider 2012, Ingold and Leifeld 2014, Bursens et al. 2014) and can draw upon sources of power such as the setting of collaborative agendas and institutional capacities (Brisbois and de Loë 2016) that other actors often do not possess. Thus, we expect governmental actors rather than nongovernmental actors to occupy central coordinator positions.

\section{CASE, DATA, AND METHODS}

\section{Case characteristics and data}

Our empirical cases cover collaboration networks in water supply governance of three administrative regions in the Swiss canton of Basel-Landschaft. Water governance is a setting that is generally prone to fragmentation (Jasny and Lubell 2015). In Switzerland, the water supply sector is strongly shaped by the federalist structure of the country: water supply is a formal responsibility of the subnational states (so-called cantons), respecting general national laws and the regulation of water quality and provision as laid out in the Constitution. When it comes to operational tasks of water distribution, provision, and infrastructure however, responsibilities typically are delegated to the municipalities.

More recently, several reforms have been initiated to regionalize water supply; that is, to encourage municipalities to comanage water supply tasks, often also involving new actors such as private companies. Consequently, regionalization increases the potential for fragmentation. Moreover, new challenges such as an increasing number of extreme events or aging infrastructure demand the inclusion of further organizations such as scientific experts or planning and engineering firms. This reorganization further increases the need for coordination and collaboration in the water sector.

In terms of case selection, studying three cases within a single subnational state holds many intervening factors constant. Reforms in terms of reorganization and regionalization of water supply, encompassing the comanagement of and shared responsibility for service supply tasks, finances, and infrastructures have been proposed in the three selected cases. The three regions represent an urban, a peri-urban, and a rural area, respectively. Whereas the first two are located in flatland areas with industrialized sites, the latter region is characterized by mountainous landscape and agriculture.

Data for our analysis of the collaboration networks stem from a survey carried out between September and December 2015 among public authorities and stakeholders involved in the water supply sector. For actor identification, we started with a preliminary interview with the subnational lead-agency. Through scoping interviews and snowball sampling conducted in late 2013 and early 2014 , the full actors list was first drawn, then validated by seven public officials and key stakeholders from the three regions. For each of the three regions, the actor list included state and federal offices, municipal authorities, waterworks, engineering companies, water providers, local water technicians, and relevant interest groups. Survey participants were considered as representatives of public or private organizations, thus answering the survey questions on behalf of a corporate actor (Coleman 1974). The only exceptions were local water technicians: though a majority were public actors, they typically carried out their task as individuals.

Respondents were asked to indicate with which other actors on the actor list they regularly collaborated in water supply management in the region. Regular collaboration was defined as either the repeated exchange of information or the joint implementation of projects. We surveyed 64 actors in the urban, 56 actors in the peri-urban, and 52 actors in the rural region. Response rates were $93 \%, 86 \%$, and $92 \%$, respectively. Based on the survey responses, we found three collaboration networks with 79 actors in the urban, 73 actors in the peri-urban, and 59 actors in the rural region. The collaboration networks include more actors than surveyed because some actors indicated nonrespondents as collaboration partners. There were many actors that were involved in all three regions. These were generally 
actors situated on higher administrative levels, such as state and national agencies or interest groups. However, their collaboration patterns were assessed for every region separately. Actors were manually assigned a dummy variable to indicate their status as governmental or nongovernmental. They were also manually assigned one of four jurisdictional levels based on an organization's main focus of operations. The four jurisdictional levels considered were local (single municipality), regional (multiple municipalities), state (across the whole state), and national (extending beyond the state of Basel-Landschaft).

We symmetrized all three networks in our analysis based on a weak criterion, establishing an undirected tie whenever one actor indicated another actor as a collaboration partner. We symmetrized the data in order to remove directed ties because the conceptual meaning of directed ties in a collaboration network is hard to interpret, given that collaboration is a process that always involves the participation of both parties. We chose weak rather than strong symmetrization because it also captures lower forms of collaboration where actors are not equally willing to call their relationship collaboration. However, such forms of collaboration capture phenomena such as access to information or sporadic contact that we expect to be a more likely form of interaction among actors of the periphery and the core.

Operationalizing periphery connectors and central coordinators The operationalization of periphery connector positions was based on assessing the number of actors that are solely connected to the network by a given actor. To do so, we assessed the effect of the removal of every actor on its own on the number of actors in newly created components apart from the main component of the network because of the actor's removal. We thus estimated the effect of node-wise deletion on an overall structural network characteristic akin to the procedure suggested by Valente and Fujimoto (2010) who locate critical connectors via edge-wise deletion.

For central coordinators, we relied on betweenness centrality (see, e.g., Borgatti and Everett 2006). Betweenness centrality measures how often an actor lies on a shortest path between any two actors it is connected to. A shortest path is defined as the connections with the minimal number of connections that an actor needs to reach another actor. For each shortest path that passes through a node, if there exist other paths that bypass the node, the contribution toward the node's betweenness centrality score of this shortest path is divided by the total number of shortest paths. Betweenness centrality measures exactly what we understand as central coordination, namely, the provision of efficient pathways within a network captured in the relative number of shortest paths running through a node.

We computed betweenness scores based on an actor's position in its respective ego network of order 2 (this includes crossconnections between all other actors an actor is connected to). This means that all other actors connected to the ego by paths of length 1 or 2 were included in our computation. Betweenness scores thus reflected an actor's position within a local ego network. The reason for focusing on ego networks is that for collaborative activities it is difficult to attach substantive meaning to path lengths longer than 2 (Gould and Fernandez 1989).

\section{Analytical steps}

In a first step, we identified the actors that were positioned within the network according to our operationalization of periphery connector and central coordination positions. We extracted ego networks and calculated betweenness scores using the $\mathrm{R}$ packages statnet (Handcock et al. 2003) and igraph (Csardi and Nepusz 2006). In order to check whether our networks exhibited a coreperiphery structure, we also partitioned the network datasets using the CORR algorithm implemented in UCINET (Borgatti et al. 2002) to assign actors to two distinct sets by maximizing the correlation between the observed and an ideal core-periphery structure.

In a second step, we carried out a statistical analysis to assess our hypotheses about the distribution of positions. It compared our observed networks to a large number of simulated networks in a permutation-based approach. In social network analysis, permutation-based approaches are used to construct null models that provide a baseline against which to compare the empirically observed networks. These permutation models aim to preserve the network structure while allowing for individual actor positions to vary (Spiro et al. 2013). For this analysis, we specified a pooled exponential random graph model (ERGM), which fit the set of parameters that on average best represent the data generating process throughout all three regions.

The pooled model was used to simulate a baseline distribution of positions that takes into account the main processes that shape the structure of the networks under study. We then compared this distribution against our observed distribution of network positions. We modeled both dyad-independent and dependent processes we theoretically expected to play a role in shaping network characteristics in our cases. We deemed the use of a pooled model, resulting in the same set of parameters for every region, to be superior to the estimation of a separate model for every case. It increased our confidence in comparing inferences based on baseline distributions generated through a process that is identical for every region because we saw no theoretical reason why the basic underlying processes shaping network structure should vary significantly between our cases.

We considered two dyad-independent processes in our model. First, we expected the respective activity of different actor types to vary. In this regard, we included terms that model activity for actors on different jurisdictional levels because we expected intermediate and lower-level actors to be more active in the network in general. Second, we also expected homophilous processes based on actor type to shape the networks. This encompasses a potential tendency for actors to favor similar actors in collaboration. In this regard, we modeled homophily among actors situated on the same jurisdictional level. We expected networks to be strongly shaped by this process because state-level actors in particular are often formally mandated to collaborate among themselves. Further, we also considered dyaddependent processes that include the propensity for triadic closure and the shape of the degree distribution because these processes are generally expected to play a role in shaping governance network structure (Robins et al. 2012).

After achieving a satisfying fit, our pooled model was used to simulate 1000 random networks for every region. These simulated networks, by the virtue of being based on a fitted model, captured 
Table 1. Number of periphery connectors and central coordinators per region and by type (governmental/nongovernmental) and jurisdictional level.

\begin{tabular}{|c|c|c|c|c|c|c|}
\hline \multirow[b]{2}{*}{ Attribute } & \multicolumn{3}{|c|}{ Periphery connectors } & \multicolumn{3}{|c|}{ Central coordinators } \\
\hline & Urban & Peri-urban & Rural & Urban & Peri-urban & Rural \\
\hline Governmental & 2 & 2 & 2 & 2 & 2 & 2 \\
\hline Nongovernmental & 2 & 2 & 1 & 4 & 1 & 1 \\
\hline Federal level & 1 & 1 & 1 & 1 & 0 & 0 \\
\hline State level & 2 & 2 & 2 & 4 & 3 & 3 \\
\hline Regional level & 0 & 0 & 0 & 0 & 0 & 0 \\
\hline Local level & 1 & 1 & 0 & 1 & 0 & 0 \\
\hline Total & 4 & 4 & 3 & 6 & 3 & 3 \\
\hline
\end{tabular}

many of the basic processes inherent in our empirical cases and therefore reflected theoretically important processes shaping network structure we wanted to control for. This enables us to assess whether our empirically observed position patterns were more likely to occur than by chance, while controlling for our modeled effects. We did so by comparing the empirically observed distribution of positions to the related distribution in the simulated networks. We analyzed two distributional patterns based on our hypotheses about factors shaping the distribution of positions. We assessed the likelihood for (a) higher level (state and national level) actors to be periphery connectors, and (b) governmental actors to be central coordinators. For reasons of comparison, we further analyzed the distributional patterns and related likelihoods of (c) governmental actors to be periphery connectors, and (d) higher level actors to be central coordinators. We estimated, simulated, and assessed goodness of fit of ERGMs using the R package xergm (Leifeld et al. 2016).

\section{RESULTS AND DISCUSSION}

\section{Distribution of positions}

All networks show a more-or-less pronounced core-periphery structure with within-core densities between 0.55 and 0.67 and within-periphery densities between 0.04 and 0.05 . This result indicates that the networks can be partitioned in a strongly connected core and a weakly connected periphery, which corresponds to our observation, based on previous studies, that in many governance situations, a well-connected group of core actors can be distinguished from a loosely connected periphery (Ernstson et al. 2008, Luthe et al. 2012, Hirschi et al. 2013).

Figure 2 shows all three collaboration networks. The identified periphery connectors and central coordinators are indicated by color. We consider an actor to be a periphery connector if the actor connects a minimum of two peripheral actors that would otherwise not be connected to the network. Further, we consider actors to be central coordinators if their betweenness scores within their respective ego network exceed a cut-off value of two standard deviations of the scaled distributions of these measures in their respective networks. We chose this cut-off value based on a sensitivity analysis (see Fig. A1.1 in Appendix 1), balancing the need of having a comparable cut-off value across regions and choosing a cut-off point at a value where small variations do not create large jumps in the number of central coordinators.

We identify four periphery connectors in the urban and peri-urban regions and three in the rural region. Six central coordinators are present in the urban region, and three in the peri-urban and rural regions. The distribution of these actors by jurisdictional level and governmental/nongovernmental status is detailed in Table 1.

The comparison of simulated distributions of actor positions versus observed values for the interaction with the set of actor attributes covered in our hypotheses is shown in Figure 3. Generally, our results are stable in their tendency across regions. This suggests that the processes generating the distribution of positions are similar across socioeconomic contexts, even though these regions differ with respect to the challenges to water supply governance.

The exact model specifications of the pooled ERGM used for baseline simulations can be found in the Appendix 1 (Table A1.1). Model fit throughout all three regions is sufficient to generate networks that are better in recreating networks of the type we observed than a model controlling only for network density. Goodness of fit plots that illustrate how far the model replicates a set of not modeled network statistics can be found in Appendix 1 (Fig. A1.2). The model is biased in two main ways because it generally creates networks that are more clustered than the observed networks and tends to produce a smaller number of isolates. This inadequacy can be expected because it reflects the minimal theoretical assumptions about drivers of network structure we incorporated into our model for all three regions. However, this issue does not present a major concern because the main purpose of the model is to create a viable baseline distribution against which to compare each observed network, and we consider the fit to be adequate for this purpose.

\section{Periphery connectors}

As compared to the simulated networks, higher level actors (national/state) are more likely to occupy network positions associated with periphery connector positions. These results thus support our first hypothesis that periphery connector positions are more likely to be occupied by higher level actors. We expected this to be the case because of the range of operations of national and state-level actors that often encompasses a broader set of other actors than it is the case for lower level actors. The empirical evidence based on the statistical models and on our analysis of specific individual roles adopted by actors such as the Federal Office for the Environment supports this idea. The integration of peripheral actors to the natural resource governance network allows for the access of sources of information heterogeneity, which has been claimed to contribute to effectiveness and adaptability (Carlsson and Sandström 2008). Some studies have 
Fig. 2. Collaboration networks in water supply for three regions in the Swiss canton of Basel-Landschaft. Colors indicate periphery connector and central coordinator positions.
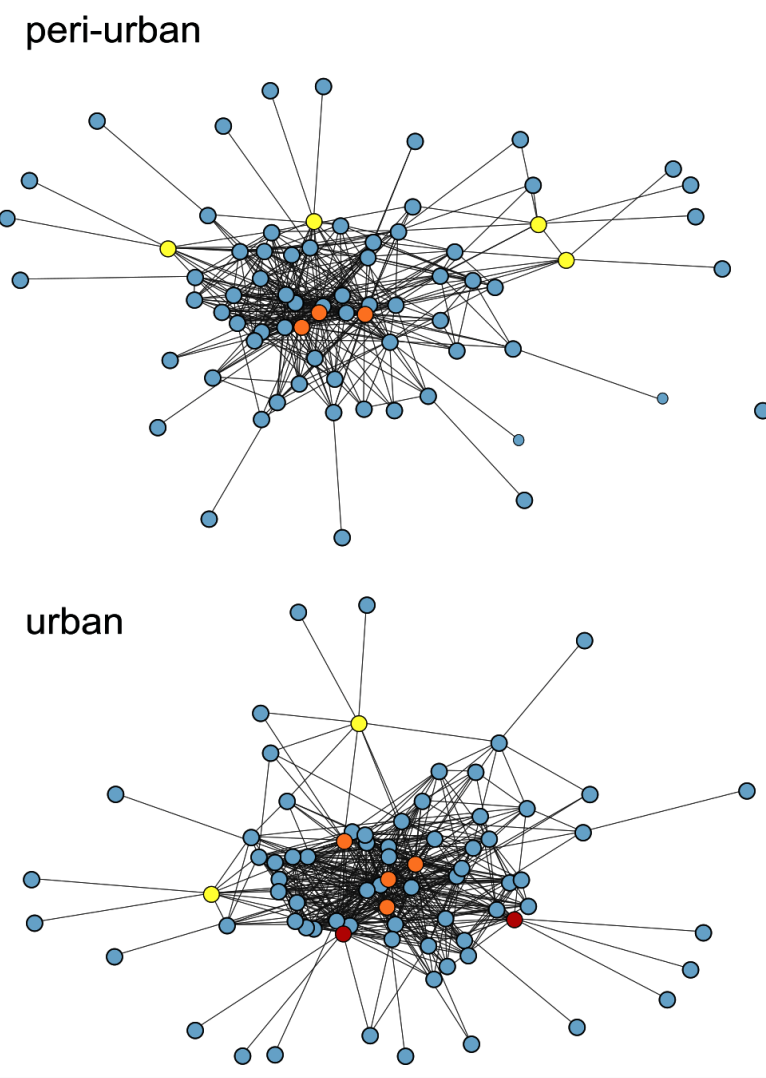

rural

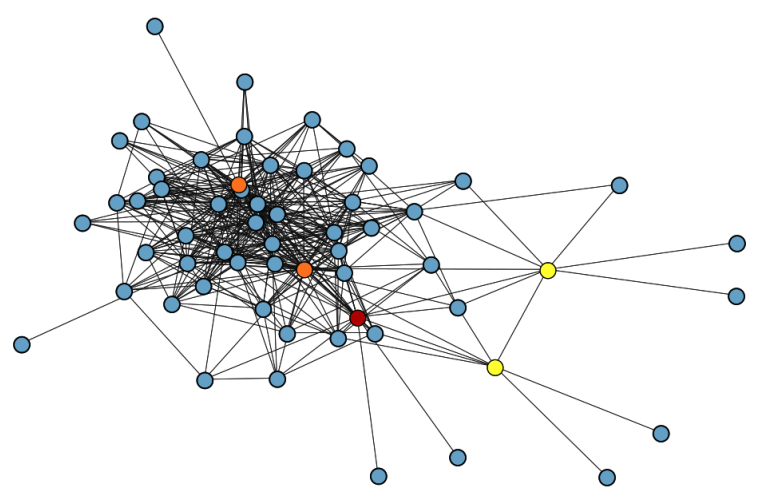

\author{
Periphery connector (PC) \\ Central coordinator (CC) \\ - Both PC and CC \\ Other actor
}

stressed that sources of new and diverse knowledge need not come from outside but can also be found among local level stakeholders (Knapp et al. 2014). However, we found no evidence that periphery connectors in our cases interact with peripheral locallevel actors. This is most likely due to the fact that there were few peripheral local-level actors in the cases we studied. It would therefore be interesting to see future research in cases where locallevel actors are less integrated into the network to elucidate the kinds of periphery connectors that build bridges to peripheral local-level actors.

We did not formulate a hypothesis on whether periphery connectors would be more likely to be governmental or nongovernmental actors. Yet, an additional finding of our study is the higher likelihood for periphery connector positions to be occupied by governmental actors. Governmental actors might have an interest in reaching out for new information. This is, for example, highlighted by Crona and Parker's (2012) study on bridging organizations, where public policy makers engaged in enhanced information- and evidence-based water management decisions because of their contacts with other types of actors. Our result showing that governance actors are more likely to occupy the position of periphery connectors should however be regarded as only tentative evidence. This is due to the fact that most of the governmental actors in the three networks under investigation are located at the national or state level, and thus considered higher level organizations. Given the specific nature of our case, we therefore feel more warranted to conclude that, in line with our first hypothesis, the higher level of actors is crucial to making them more likely to be periphery connectors. These positions might just as likely be occupied by nongovernmental, higher level actors in cases where these are more prevalent. This might be especially true for cases including transnational settings, where higher level, nongovernmental actors have been shown to assume important roles in policy processes (Tantivess and Walt 2008).

A closer look at the actors occupying periphery connector positions shows that our measure identifies a meaningful set of actors. The Federal Office for the Environment (FOEN) has a periphery connector position in all regions. For the purpose of illustration, the position of the FOEN in its respective ego network of order two is shown in Figure 4. Albeit the FOEN is not a central actor, it is the only actor that connects two national actors to a number of central state-level agencies in the network. The two national actors that only collaborate with the FOEN are two organizations dedicated to interstate coordination within the federal system. These are the KVU and BPUK, which are the conferences of heads of Swiss state agencies for environmental protection and spatial protection, respectively. Both of these organizations are good examples in terms of actors who are not involved in day-to-day management of water supply but may be of importance for giving access to a broader network of actors, for example, to disseminate good practices learned in other states. Moreover, the FOEN itself collaborates directly with another 
Fig. 3. Frequency (count) of the occurence of four actor types in three Swiss water supply governance networks. The solid lines show the real, observed number of each actor type. The bars illustrate the distribution obtained from 1000 simulated networks based on a pooled exponential random graph model of the networks. The more the solid line deviates to the right from the distribution, the more likely it is that the given actor type is observed more often than by chance.
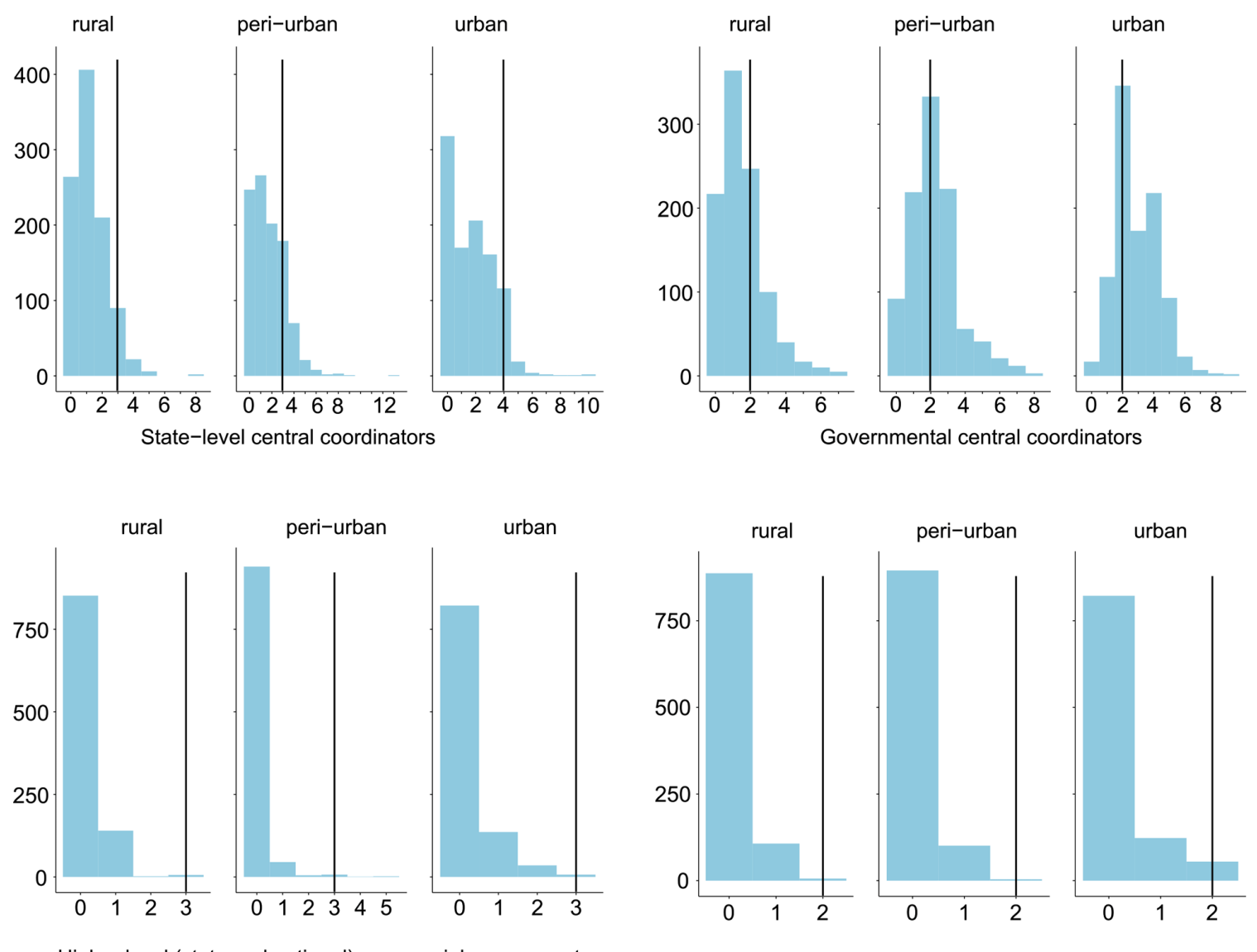

Higher level (state and national) core-periphery connectors

Governmental core-periphery connectors

important periphery connector in all regions, the state-level fishery association (KFVBL). The state-level fishery association integrates the two nature protection organizations present in all regions (Pro Natura [PN_BL] and WWF) into the network. Thus, the viewpoints of nature protection organizations are highly likely to be passed through the fishery association. In highlighting the special role of fishery associations in water policy fields, this result is similar to previous research on policy networks surrounding marine-protected areas in California (Weible and Sabatier 2005).

\section{Central coordinators}

The results of our inferential analysis suggest a slightly higher likelihood for central coordinator positions to be occupied by governmental actors but the empirical evidence should be seen as a tendency rather than a clear pattern. The results therefore provide only weak support for our second hypothesis, as the observed number of central coordinators equals the mean of the distribution obtained through the permutations in the peri-urban and urban regions.

Especially when governmental actors are located at the national level, they do not occupy coordinating positions, whereas state- level governmental actors do so. In singling out governmental actors the study is in line with findings in Ernstson et al. (2010) who found municipal and regional governmental actors to be most active in efforts to induce collaborative governance of urban green areas in Stockholm. The level of involvement of governmental actors also depends on the nature of what is governed. A study of network governance among actors involved in tourism in the Swiss Gotthard region, where the legal requirements for governmental involvement are less far-reaching than for natural resources, they played a lesser (though still pronounced) coordinator role (Luthe et al. 2012).

Another finding of our analysis is that in all regions, private and public actors at the state-level, in contrast to the national, regional, and local levels, tend to occupy central coordinator positions. Results further indicate that the state level is likely to be the decisive level for coordinating collaboration in Swiss water governance. A possible explanation for this finding is that statelevel actors directly interact with local-level stakeholders (as opposed to most national-level actors) but do so in various numbers of local settings (as opposed to local- and regional-level 
Fig. 4. Ego network (order two) of collaboration ties of the Swiss Federal Office for the Environment (FOEN, indicated by red circle) in the water supply governance network of a peri-urban region in the Swiss canton of Basel-Landschaft. The figure illustrates the periphery connector role of the FOEN. KVU and BPUK are the conferences of heads of Swiss state agencies for environmental protection and spatial protection, respectively. The node labeled KFVBL represents the state level fishery association, itself a periphery connector. It integrates two nature protection organizations (PN_BL and WWF) into the network.

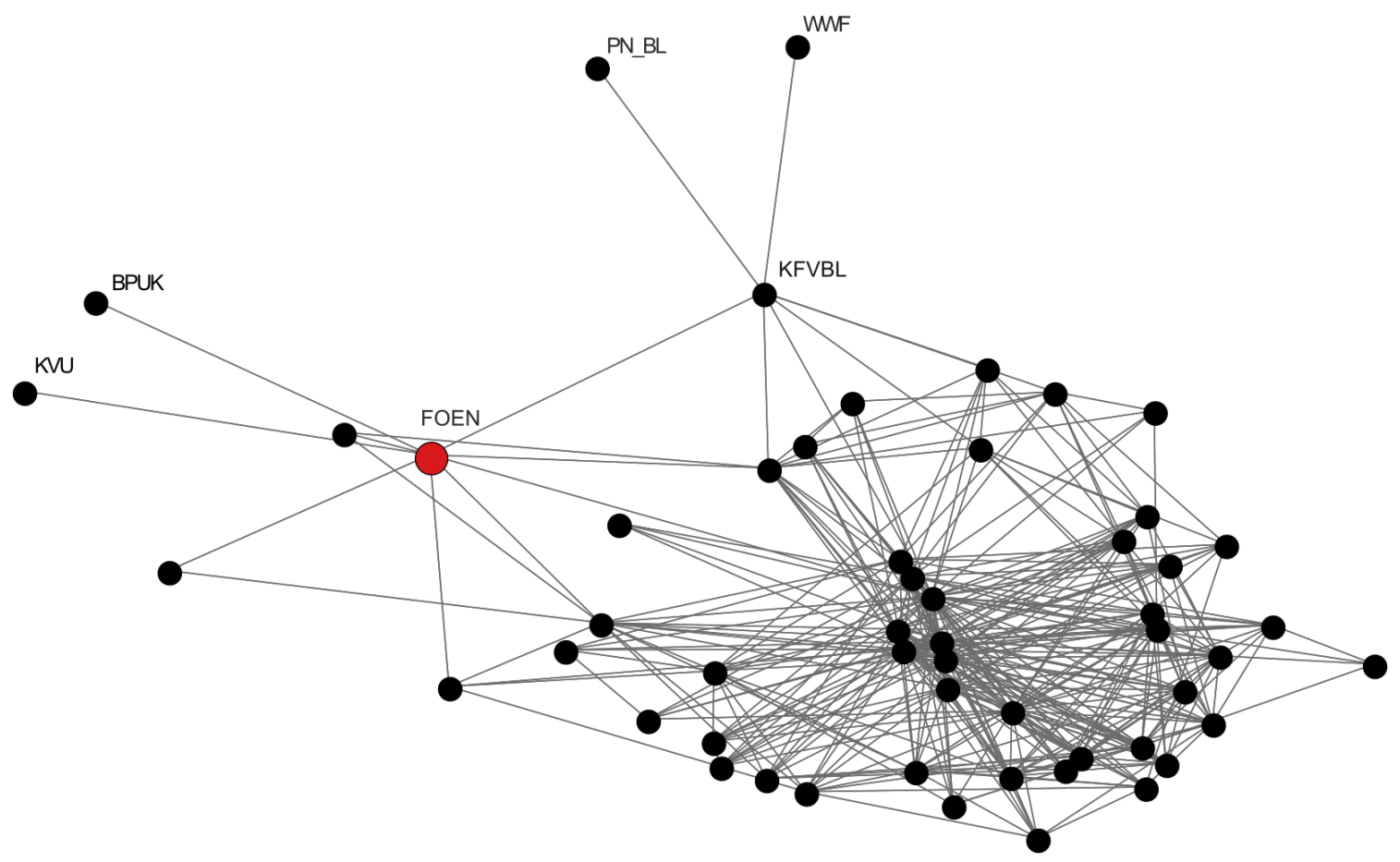

actors). This mixture of perspectives, direct local involvement, broader oversight, provides state-level actors with the capacity to play a coordinating role. Although our results do not readily transfer to other, especially nonfederalist settings, it is plausible that the mixture of these two different perspectives is a more general pattern inducing coordinative activity that should also be found elsewhere. A similar finding is reported by Ingold's (2014) study on regional Swiss flood prevention and land use policies: state-level actors played a crucial role in connecting the local and the national level during the top-down implementation of regional projects.

\section{Actors occupying both positions}

There are two actors in the urban and three in the rural regions who occupy positions that enable them to adopt periphery connector as well as central coordinator positions. In the rural region, one of them is the state-level utilities agency (AIB). This agency is situated in the periphery of the network, but has ties to many core actors and to other important peripheral actors, such as the FOEN or the state-level fishery association. Beyond this, it exclusively collaborates with two regional engineering and consulting firms.

In the urban region, a look at the only local-level actor occupying both a central coordinator as well as periphery connector position further illustrates both concepts. The actor is a municipal local water technician working for a larger municipality. Taking a closer look at the position and activities of this actor shows that this technician is the only actor who collaborates regularly with the local university in the region because of a project mapping groundwater streams. This exemplifies an important aspect of its periphery connector position, that is, to bring external knowledge into the governance network. The water technician also has an above-average amount of connections to other municipalities and geographically adjacent local actors. In the context of this specific case, the large amount of connections can be explained by the hydrologically important position of the technician's municipality within the region. The municipal territory entails the most important regional groundwater recharge area as well as the site of an accidental fire in a chemical storage facility leading to a significant chemical spill in 1986 that is still being monitored.

\section{CONCLUSION}

In this paper, we have investigated periphery connectors and central coordinators as two specific bridging actor positions that connect actors in governance settings with a high potential for fragmentation. Studying decentralized regional water supply governance structures in Switzerland with high potential for fragmentation, we have shown an effective formal way of operationalizing both positions, based on betweenness centrality computed on ego networks, and a simple node deletion procedure. Further, we have demonstrated that both bridging positions are more likely to be occupied by some actors than others in three important ways. 
First, when it comes to overcoming fragmentation, higher level actors provide crucial access to heterogeneity. Higher level actors were more likely to be periphery connectors in our cases, connecting organizations not involved in the day-to-day operations of water supply management to a regional governance network. These actors can provide potential inputs for pluralistic thinking and innovation. Second, governmental actors are more likely than others to be central coordinators. This is in line with previous research on governance and policy networks that has argued that governmental actors remain "special" in these networks (Calanni et al. 2014, Fischer 2017), even taking into account a proposed shift from governance to governance (Rhodes 1996) with a more limited role for governmental actors. Governmental actors are able to draw upon sources of power that are inaccessible to other actors, which influences collaborative processes and should therefore be taken in account in their analysis (Brisbois and de Loë 2016). Third, actors are most likely to provide central coordination if they are located at the subnational, state level. We argued that this is due to the mixture of specific oversight functions (for governmental actors) and the combination of local level involvement and a broader perspective that accrues at the state level. Thus, even in contexts where the institutional setting provides barriers for hierarchical coordination, overcoming fragmentation through collaboration remains a task that is mediated by state-level actors.

The aim of our analysis was to show that in a given natural resource governance setting, it pays to look beyond the institutional arrangement to the existing setting of collaboration among actors. Institutional and policy change might be one means to overcome fragmentation, but it could sometimes be more effective to tweak an existing setting by encouraging the activities of, and facilitate interactions between certain individual actors (Borg et al. 2015). In this context, we have also identified governmental and higher level actors as promising candidates for such a task.

Our analysis has important limitations that should be addressed in future research. First, our results proved reasonably robust across three cases that differ along a continuum from urban to rural regions. Still, as we observe a degree of variation between regions, this points to the value of analyzing further contextual conditions. Among further conditions that might influence the capacity and willingness of actors to occupy different network positions could be the level of conflict (Weible et al. 2010) or the institutional specificities in the respective project set-up, such as comparing top-down versus bottom-up approaches (Ingold 2014). Furthermore, our research design held the substantive sector (water supply), and state-level as well as national-level institutional factors constant. The specific setting of Switzerland as a country with well-functioning institutions, professional government agencies, and a high level of trust in public agencies needs to be acknowledged (Kriesi and Trechsel 2008, Sciarini et al. 2015). This setting makes it very likely that governmental actors are highly active in governance networks because of legal requirements and their specific capabilities and the results pertaining to the role of governmental actors may thus not transfer readily to settings with weak institutions. However, even in settings with weak institutions, higher level actors could have access to a broader and more heterogeneous actor set than local level stakeholders.
Second, there is a notion of causality inherent to all of our hypotheses that sees actors as individual agents making an informed, purposeful decision to assume a position associated with a certain role based on their varying goals or incentives. This methodologically individualistic logic could however also be reversed, as an actor might not make a purposeful decision to become a coordinator or periphery connector or even perceive itself as one, but could simply end up in a given network position based on the accumulated decisions by other actors that lead it to end up there without making any strategic choice. In reality, a combination of both of these forces, individual decision making and structural opportunity structures, are probably at play. Future analyses should aim at disentangling the direction of causality inherent to all our hypotheses to explore further how a given network structure originates between individual-level agency and structural, contextual factors.

Third, our justification for researching actor roles that help to overcome fragmentation rests on the assumption that overcoming fragmentation contributes to outcomes, notably effective governance through improved coordination and access to new knowledge. This provides the underlying, normative justification for research on the topic. However, we did not directly study outcomes in our research and are thus unable to further scrutinize this assumption. Specifying the causal pathways through which different actors contribute to specific governance outcomes thus remains a crucial field for future research.

Responses to this article can be read online at: http://www.ecologyandsociety.org/issues/responses. php/10030

\section{Acknowledgments:}

This work was supported by the Swiss National Science Foundation (project numbers 100010 and 149410), the Canton of BaselLandschaft, and the Competence Centre for Drinking Water at Eawag, the Swiss Federal Institute of Aquatic Science and Technology. We would like to thank the two anonymous reviewers and the editorial team of Ecology and Society for their helpful feedback on earlier versions of this article.

\section{LITERATURE CITED}

Angst, M., and C. Hirschi. 2016. Network dynamics in natural resource governance: a case study of Swiss landscape management. Policy Studies Journal 45(2):315-336 http://dx.doi. org/10.1111/psj.12145

Bäckstrand, K. 2008. Accountability of networked climate governance: the rise of transnational climate oartnerships. Global Environmental Politics 8(3):74-102. http://dx.doi.org/10.1162/ glep.2008.8.3.74

Berardo, R. 2014. The evolution of self-organizing communication networks in high-risk social-ecological systems. International Journal of the Commons 8(1):236-258 http://dx.doi. org/10.18352/ijc.463 
Betsill, M. M., and H. Bulkeley. 2004. Transnational networks and global environmental governance: the cities for climate protection program. International Studies Quarterly 48 (2):471-493. http://dx.doi.org/10.1111/j.0020-8833.2004.00310.x

Bodin, Ö., and B. I. Crona. 2009. The role of social networks in natural resource governance: What relational patterns make a difference? Global Environmental Change 19(3):366-374. http:// dx.doi.org/10.1016/j.gloenvcha.2009.05.002

Bodin, Ö., B. Crona, M. Thyresson, A.-L. Golz, and M. Tengö. 2014. Conservation success as a function of good alignment of social and ecological structures and processes. Conservation Biology 28(5):1371-1379. http://dx.doi.org/10.1111/cobi.12306

Bolleyer, N., and T. A. Börzel. 2010. Non-hierarchical policy coordination in multilevel systems. European Political Science Review 2(2):157-185. http://dx.doi.org/10.1017/S175577391000007X

Borg, R., A. Toikka, and E. Primmer. 2015. Social capital and governance: a social network analysis of forest biodiversity collaboration in Central Finland. Forest Policy and Economics 50:90-97. http://dx.doi.org/10.1016/i.forpol.2014.06.008

Borgatti, S. P., and M. G. Everett. 2006. A graph-theoretic perspective on centrality. Social Networks 28(4):466-484. http:// dx.doi.org/10.1016/j.socnet.2005.11.005

Borgatti, S. P., M. G. Everett, and L. C. Freeman. 2002. UCINET for Windows: software for social network analysis. Analytic Technologies, Harvard, Massachusetts, USA.

Brisbois, M. C., and R. C. de Loë. 2016. Power in collaborative approaches to governance for water: a systematic review. Society \& Natural Resources 29(7):775-790. http://dx.doi. org/10.1080/08941920.2015.1080339

Bursens, P., J. Beyers, and T. Donas. 2014. Domestic European Union coordination and interest group mobilization in three member states: looking beyond the formal mechanisms. Regional \& Federal Studies 24(3):363-381. http://dx.doi.org/10.1080/13597566.2014.911739

Burt, R. S., M. Kilduff, and S. Tasselli. 2013. Social network analysis: foundations and frontiers on advantage. Annual Review of Psychology 64(1):527-547. http://dx.doi.org/10.1146/annurevpsych-113011-143828

Calanni, J. C., S. N. Siddiki, C. M. Weible, W. D. Leach. 2014. Explaining coordination in collaborative partnerships and clarifying the scope of the belief homophily hypothesis. Journal of Public Administration Research and Theory 25(3):901-927. http://dx.doi.org/10.1093/jopart/mut080

Carlsson, L. G., and A. C. Sandström. 2008. Network governance of the commons. International Journal of the Commons 2 (1):33-54. http://dx.doi.org/10.18352/ijc.20

Cash, D. W., W. N. Adger, F. Berkes, P. Garden, L. Lebel, and P. Olsson. 2006. Scale and cross-scale dynamics: governance and information in a multilevel world. Ecology and Society 11(2):8. http://dx.doi.org/10.5751/ES-01759-110208

Christopoulos, D., and K. Ingold. 2015. Exceptional or just well connected? Political entrepreneurs and brokers in policy making. European Political Science Review 7(3):475-498. http://dx.doi. org/10.1017/S1755773914000277
Coleman, J. S. 1974. Power and the structure of society. Norton, New York, New York, USA.

Crona, B. I., and J. N. Parker. 2012. Learning in support of governance: theories, methods, and a framework to assess how bridging organizations contribute to adaptive resource governance. Ecology and Society 17(1):32. http://dx.doi. org/10.5751/ES-04534-170132

Csardi, G., and T. Nepusz. 2006. The igraph software package for complex network research. InterJournal Complex Sy:1695.

Ekstrom, J. A., and O. R. Young. 2009. Evaluating functional fit between a set of institutions and an ecosystem. Ecology and Society 14(2):16. http://dx.doi.org/10.5751/ES-02930-140216

Ernstson, H., S. Barthel, E. Andersson, and S. T. Borgström. 2010. Scale-crossing brokers and network governance of urban ecosystem services: the case of Stockholm. Ecology and Society 15(4):28. http://dx.doi.org/10.5751/ES-03692-150428

Ernstson, H., S. Sörlin, and T. Elmqvist. 2008. Social movements and ecosystem services: the role of social network structure in protecting and managing urban green areas in Stockholm. Ecology and Society 13(2):39. http://dx.doi.org/10.5751/ ES-02589-130239

Fernandez, R. M., and R. V. Gould. 1994. A dilemma of state power: brokerage and influence in the national health policy domain. American Journal of Sociology 99(6):1455-1491. http:// dx.doi.org/10.1086/230451

Fischer, M. 2017. Institutions and policy networks in Europe. Pages 833-854 in J. N. Victor, A. H. Montgomery, and M. Lubell, editors. The Oxford handbook of political networks. Edited by Oxford University Press, Oxford, UK.

Fischer, M., M. Angst, and S. Maag. 2017. Co-participation in Swiss water policy forums. International Journal of Water Resources Development. http://dx.doi.org/10.1080/07900627.2017.1374929

Fischer, M., and I. Schläpfer. 2017. Metagovernance and policy forum outputs in Swiss environmental politics. Environmental Politics 26(5):870-892. http://dx.doi.org/10.1080/09644016.2017.1284981

Fliervoet, J. M., G. W. Geerling, E. Mostert, and A. J. M. Smits. 2016. Analyzing collaborative governance through social network analysis: a case study of river management along the Waal River in The Netherlands. Environmental Management 57(2):355-367. http://dx.doi.org/10.1007/s00267-015-0606-X

Folke, C., T. Hahn, P. Olsson, and J. Norberg. 2005. Adaptive governance of social-ecological systems. Annual Review of Environment and Resources 30(1):441-473. http://dx.doi. org/10.1146/annurev.energy.30.050504.144511

Folke, C., L. Pritchard, F. Berkes, J. Colding, and U. Svedin. 2007. The problem of fit between ecosystems and institutions: ten years later. Ecology and Society 12(1):30. http://dx.doi.org/10.5751/ ES-02064-120130

Gould, R. V., and R. M. Fernandez. 1989. Structures of mediation: a formal approach to brokerage in transaction networks. Sociological Methodology 19:89-126. http://dx.doi. org/10.2307/270949

Granovetter, M. S. 1973. The strength of weak ties. American Journal of Sociology 78:1360-1380. http://dx.doi.org/10.1086/225469 
Handcock, M. S., D. R. Hunter, C. T. Butts, S. M. Goodreau, and M. Morris. 2003. statnet: software tools for the statistical modeling of network data. Seattle, Washington, USA.

Hirschi, C., A. Widmer, S. Briner, and R. Huber. 2013. Combining policy network and model-based scenario analyses: an assessment of future ecosystem goods and services in Swiss mountain regions. Ecology and Society 18(2):42. http://dx.doi.org/10.5751/ ES-05480-180242

Ingold, K. 2014. How involved are they really? A comparative network analysis of the institutional drivers of local actor inclusion. Land Use Policy 39:376-387. http://dx.doi.org/10.1016/ j.landusepol.2014.01.013

Ingold, K., and P. Leifeld. 2014. Structural and institutional determinants of influence reputation: a comparison of collaborative and adversarial policy networks in decision making and implementation. Journal of Public Administration Research and Theory 26(1):1-18. http://dx.doi.org/10.1093/jopart/muu043

Jasny, L., and M. Lubell. 2015. Two-mode brokerage in policy networks. Social Networks 41:36-47. http://dx.doi.org/10.1016/j. socnet.2014.11.005

Kininmonth, S., A. Bergsten, and Ö. Bodin. 2015. Closing the collaborative gap: aligning social and ecological connectivity for better management of interconnected wetlands. AMBIO 44 (1):138-148. http://dx.doi.org/10.1007/s13280-014-0605-9

Klijn, E. H., and J. F. M. Koppenjan. 2000. Public management and policy networks. Public Management: An International Journal of Research and Theory 2(2):135-158. http://dx.doi. org/10.1080/14719030000000007

Knapp, C. N., F. S. Chapin III, G. P. Kofinas, N. Fresco, C. Carothers, and A. Craver. 2014. Parks, people, and change: the importance of multistakeholder engagement in adaptation planning for conserved areas. Ecology and Society 19(4):16. http:// dx.doi.org/10.5751/ES-06906-190416

Kriesi, H., and A. H. Trechsel. 2008. The politics of Switzerland: continuity and change in a consensus democracy. Cambridge University Press, Cambridge, UK. http://dx.doi.org/10.1017/ CBO9780511790676

Leifeld, P., S. J. Cranmer, and B. A. Desmarais. 2016. xergm: Extensions for exponential random graph models.

Leifeld, P., and V. Schneider. 2012. Information exchange in policy networks. American Journal of Political Science 56(3):731-744. http://dx.doi.org/10.1111/j.1540-5907.2011.00580.x

Lubell, M. 2013. Governing institutional complexity: the ecology of games framework. Policy Studies Journal 41(3):537-559. http:// dx.doi.org/10.1111/psj.12028

Luthe, T., R. Wyss, and M. Schuckert. 2012. Network governance and regional resilience to climate change: empirical evidence from mountain tourism communities in the Swiss Gotthard region. Regional Environmental Change 12(4):839-854. http://dx.doi. org/10.1007/s10113-012-0294-5

McAllister, R. R. J., R. McCrea, and M. N. Lubell. 2014. Policy networks, stakeholder interactions and climate adaptation in the region of south east Queensland, Australia. Regional Environmental Change 14(2):527-539. http://dx.doi.org/10.1007/ s10113-013-0489-4

McAllister, R. R. J., B. M. Taylor, and B. P. Harman. 2015. Partnership networks for urban development: how structure is shaped by risk. Policy Studies Journal 43(3):379-398. http://dx. doi.org/10.1111/psj.12103

Newig, J., and O. Fritsch. 2009. Environmental governance: participatory, multi-level - and effective? Environmental Policy and Governance 19:197-214. http://dx.doi.org/10.1002/eet.509

Ostrom, E. 2000. Collective action and the evolution of social norms. Journal of Economic Perspectives 14(3):137-158. http://dx. doi.org/10.1257/jep.14.3.137

Ostrom, E. 2009. A general framework for analyzing sustainability of social-ecological systems. Science 325 (5939):419-422. http://dx.doi.org/10.1126/science.1172133

Pahl-Wostl, C. 2009. A conceptual framework for analysing adaptive capacity and multi-level learning processes in resource governance regimes. Global Environmental Change 19(3):354-365. http://dx.doi.org/10.1016/j.gloenvcha.2009.06.001

Prell, C., K. Hubacek, and M. Reed. 2009. Stakeholder analysis and social network analysis in natural resource management. Society \& Natural Resources 22(6):501-518. http://dx.doi. org/10.1080/08941920802199202

Rathwell, K. J., and G. D. Peterson. 2012. Connecting social networks with ecosystem services for watershed governance: a social-ecological network perspective highlights the critical role of bridging organizations. Ecology and Society 17(2):24. http:// dx.doi.org/10.5751/ES-04810-170224

Rhodes, R. A. W. 1996. The new governance: governing without government. Political Studies 44:652-667. http://dx.doi. org/10.1111/j.1467-9248.1996.tb01747.x

Robins, G., J. M. Lewis, and P. Wang. 2012. Statistical network analysis for analyzing policy networks. Policy Studies Journal 40 (3):375-401. http://dx.doi.org/10.1111/j.1541-0072.2012.00458.x

Sciarini, P., M. Fischer, and D. Traber. 2015. Political decisionmaking in Switzerland. The consensus model under pressure. Palgrave Macmillan, London, UK. http://dx.doi. org/10.1057/9781137508607

Spiro, E. S., R. M. Acton, and C. T. Butts. 2013. Extended structures of mediation: re-examining brokerage in dynamic networks. Social Networks 35(1):130-143. http://dx.doi. org/10.1016/j.socnet.2013.02.001

Tantivess, S., and G. Walt. 2008. The role of state and non-state actors in the policy process: the contribution of policy networks to the scale-up of antiretroviral therapy in Thailand. Health Policy and Planning 23(5):328-338. http://dx.doi.org/10.1093/heapol/ czn023

Valente, T. W., and K. Fujimoto. 2010. Bridging: locating critical connectors in a network. Social Networks 32(3):212-220. http:// dx.doi.org/10.1016/j.socnet.2010.03.003

Vignola, R., T. L. McDaniels, and R. W. Scholz. 2013. Governance structures for ecosystem-based adaptation: using 
policy-network analysis to identify key organizations for bridging information across scales and policy areas. Environmental Science \& Policy 31:71-84. http://dx.doi.org/10.1016/j.envsci.2013.03.004

Weible, C. M., A. Pattison, and P. A. Sabatier. 2010. Harnessing expert-based information for learning and the sustainable management of complex socio-ecological systems. Environmental Science \& Policy 13(6):522-534. http://dx.doi.org/10.1016/j. envsci.2010.05.005

Weible, C. M., and P. A. Sabatier. 2005. Comparing policy networks: marine protected areas in California. Policy Studies Journal 33(2):181-202. http://dx.doi.org/10.1111/j.1541-0072.2005.00101. 


\section{Appendix 1: Sensitivity analyses and ERGM results}

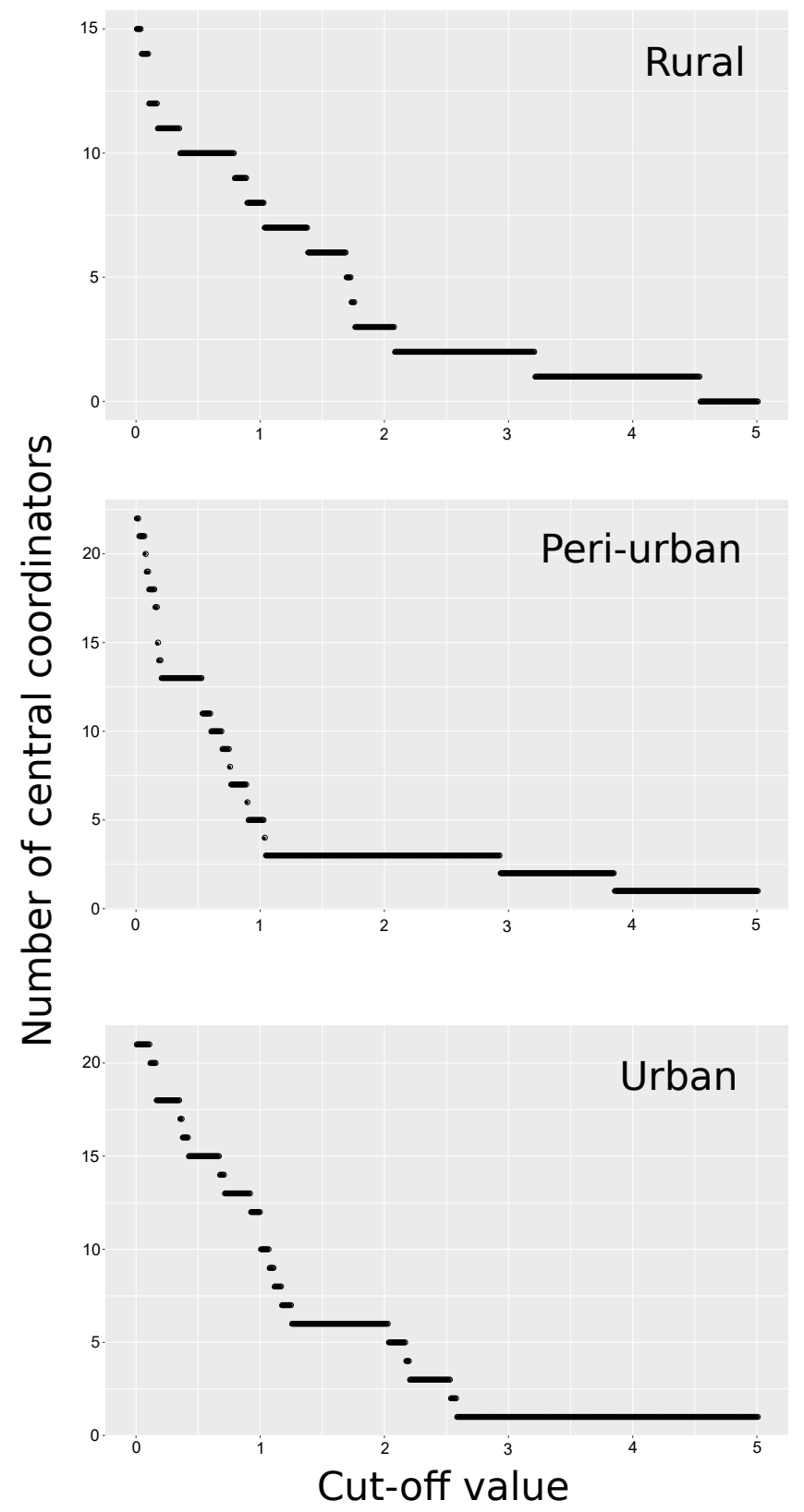

Figure A1.1: Sensitivity analyses for number of central coordinators depending on variation in cut-off values (standard deviations above mean ego betweenness score) for rural, peri-urban, and urban region 


\begin{tabular}{lc}
\hline & Model 1 \\
\hline Edges & $-3.25^{*}$ \\
Geometrically weighted $(\alpha=0.5)$ edgewise shared partners & {$[-4.55 ;-2.57]$} \\
& $1.60^{*}$ \\
Geometrically weighted $(\alpha=1.2)$ degree & $1.34 ; 2.27]$ \\
& $-6.87^{*}$ \\
Geometrically weighted $(\alpha=0.1)$ dyad-wise shared partners & {$[-7.85 ;-5.80]$} \\
isolates & $-0.10^{*}$ \\
State level activity & $-0.10 ;-0.09]$ \\
& $-27.42^{*}$ \\
Regional level activity & $-31.52 ;-28.42]$ \\
& $0.38^{*}$ \\
Local level activity & {$[0.10 ; 0.61]$} \\
& $0.40^{*}$ \\
Level homophily & {$[0.23 ; 0.48]$} \\
& 0.00 \\
& {$[-0.10 ; 0.09]$} \\
*0 outside the confidence interval & 0.04 \\
\end{tabular}

Table A1.1: Coefficients of pooled exponential random graph model used to generate baseline distributions in permuta-tional analysis. Confidence intervals in square brackets 

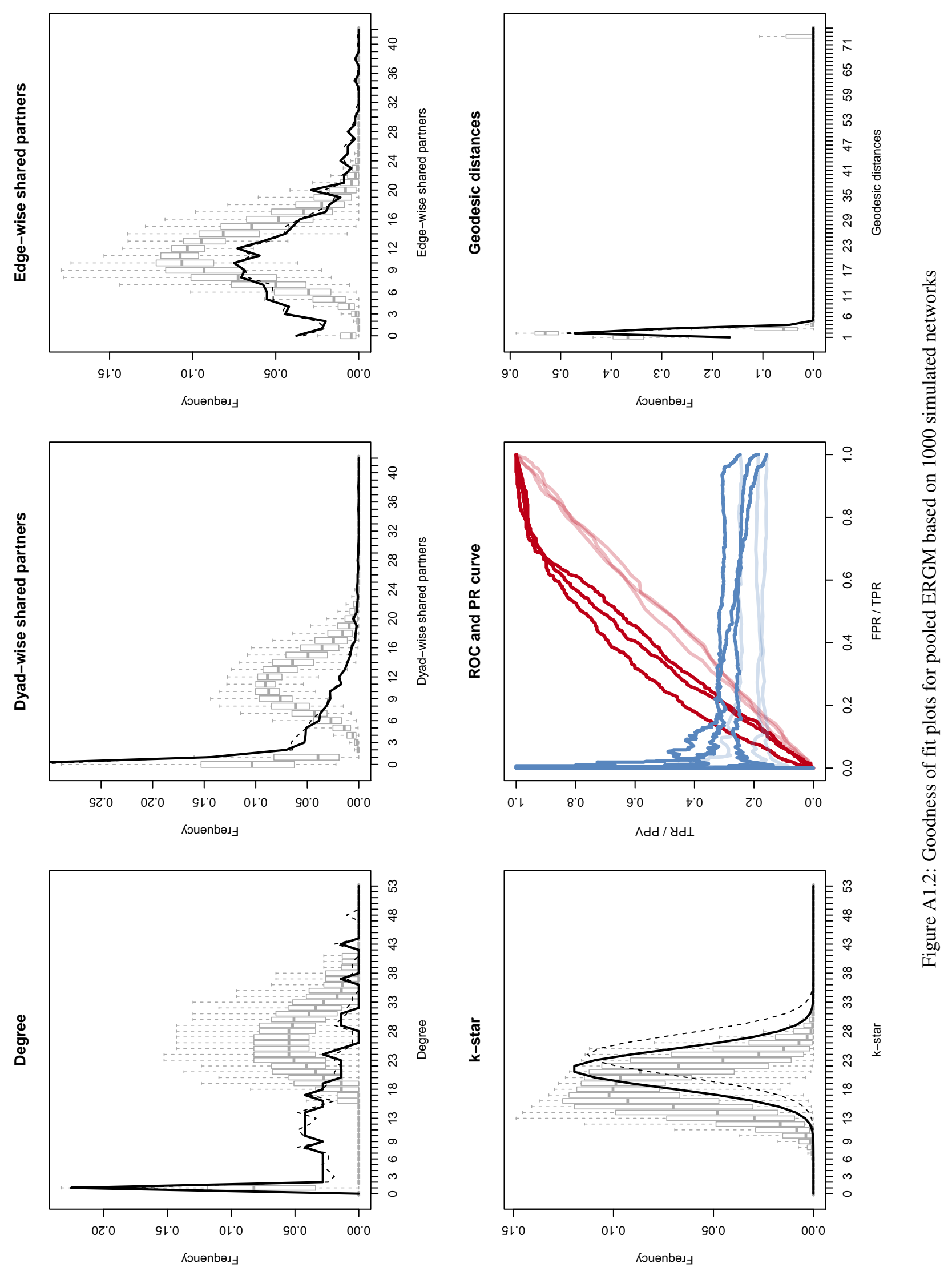